\title{
Effectiveness of multi-ingredient supplement on substrate utilisation, perception of hunger, mood state and rate of perceived exertion (RPE) at rest and during exercise
}

\author{
Marcos Seijo ${ }^{1 *}$, Eneko Larumbe ${ }^{2}$, Ahmad Alkhatib $^{3}$, Fernando Naclerio ${ }^{1}$ \\ From The Twelfth International Society of Sports Nutrition (ISSN) Conference and Expo \\ Austin, TX, USA. 11-13 June 2015
}

\section{Background}

Enhancing the ability to utilize fatty acids at rest and during exercise is a known important factor for weight loss and endurance performance outcomes. The aim of this study was to determine the acute effect of a multiingredient supplement (Shred-Matrix ${ }^{\mathbb{B}}$ ), containing green tea extract, yerba mate, guarana seed extract, anhydrous caffeine, saw palmetto, fo-ti, eleuthero root, cayenne pepper, and yohimbine $\mathrm{HCI}$, on fatty acid oxidation (FAO), perception of hunger, mood state and rate of perceived exertion (RPE) at rest and during 30 min of submaximal exercise.

\section{Methods}

Following the ethical institutional approval and after performing an incremental test to exhaustion to determine both their peak oxygen uptake $\left(\mathrm{VO}_{2}\right.$ peak) and the exercise intensity where fat oxidation becomes maximal (Fmax), twelve healthy recreationally active participants, 5 females and 7 males (MS \pm SD age: $24 \pm 3.8$; Body Mass $69 \pm 17.0 \mathrm{~kg}$, stature $174 \pm 0.09 \mathrm{~cm}$ ) performed two experimental ergometry cycling trials $72 \mathrm{~h}$ apart. Following an overnight fast, participants were randomised to ingest $1.5 \mathrm{~g}$ ( $3 \times$ capsules $)$ of either a multi-ingredient supplement (SHRED) or placebo (PL). On both occasions, participants rested for 3 hours and then performed a constant 30-min cycling exercise test corresponding to their individually-determined Fmax intensity.

\footnotetext{
*Correspondence: M.Seijo@greenwich.ac.uk

'Centre for Sports Science and Human Performance, School of Science,

University of Greenwich, Chatham Maritime, Kent, UK

Full list of author information is available at the end of the article
}

Expired gasses and stoichiometric indirect calorimetry were used to analyse fatty acid oxidation (FAO) at rest and during exercise. The rate of perceived exertion (RPE) using the Borg scale (6-20) was measured every 3 min during the 30-min exercise. Additionally both mood state and perception of hunger were assessed just after the ingestion (-3h before exercise), immediately pre and post exercise. A repeated measures ANOVA design and Cohen $\mathrm{d}$ effect sizes were used to analyse potential differences between times and treatment conditions.

\section{Results}

Perception of hunger and mood state were not different between conditions. With the exception of the first $3 \mathrm{~min}$ time point, all RPE values were significantly lower in SHRED compared to $\mathrm{Pl}(\mathrm{p}<0.001)$. FAO increased in SHRED from $-3 \mathrm{~h}$ to pre [0.56 (0.26) to $0.96(0.37), \mathrm{p}=$ $0.003 \mathrm{~d} 1.34]$ but not in PL [0.67 (0.25) to $0.74(0.19) \mathrm{p}=$ $0.334 \mathrm{~d}=0.49$. Both conditions showed a significant increase in FAO from pre to post exercise [SHRED 0.96 (0.37) to $3.80(1.92) \mathrm{p}<0.01 \mathrm{~d}=1.72$; Pl $0.74(0.19)$ to $2.80(2.02) \mathrm{p}=0.009 \mathrm{~d}=1.09]$ with no differences between them $(\mathrm{p}=0.12 \mathrm{~d}=0.49)$.

\section{Conclusion}

Acute ingestion of SHRED increases FAO significantly at rest, and appears to have a moderate effect size on FAO during exercise compared with PL. Those effects were combined with a significant decrease in the perception of effort during Fmax exercise intensity, but did not affect mood state and perception of hunger. The results suggest an acute effectiveness of the multi-ingredient supplement 
(Shred-Matrix ${ }^{\circledR}$ ) in augmenting the weight-loss benefits at rest and during exercise.

\section{Authors' details}

${ }^{1}$ Centre for Sports Science and Human Performance, School of Science, University of Greenwich, Chatham Maritime, Kent, UK. ${ }^{2}$ Clinical Research Institute, Texas Tech University Health Science Center, Lubbock, TX, USA. ${ }^{3}$ Sport Science Program, College of Arts and Sciences, Qatar University,

Doha, P.O. Box 2713, Qatar.

Published: 21 September 2015

doi:10.1186/1550-2783-12-S1-P42

Cite this article as: Seijo et al.: Effectiveness of multi-ingredient

supplement on substrate utilisation, perception of hunger, mood state

and rate of perceived exertion (RPE) at rest and during exercise. Journal

of the International Society of Sports Nutrition 2015 12(Suppl 1):P42.

Submit your next manuscript to BioMed Central and take full advantage of:

- Convenient online submission

- Thorough peer review

- No space constraints or color figure charges

- Immediate publication on acceptance

- Inclusion in PubMed, CAS, Scopus and Google Scholar

- Research which is freely available for redistribution

Submit your manuscript at www.biomedcentral.com/submit 